Chapman University

Chapman University Digital Commons

Pharmacy Faculty Articles and Research

School of Pharmacy

2013

\title{
Multifunctional Hydroxyapatite and Poly(D,L- Lactide-co-Glycolide) Nanoparticles for the Local Delivery of Cholecalciferol
}

Nenad Ignjatović

Serbian Academy of Sciences and Arts, nenad.ignjatovic@itn.sanu.ac.rs

Vuk Uskoković

Chapman University, uskokovi@chapman.edu

Zorica Ajduković

University of Niš

Dragan Uskoković

Serbian Academy of Sciences and Arts

Follow this and additional works at: http://digitalcommons.chapman.edu/pharmacy_articles

Part of the Animals Commons, Musculoskeletal System Commons, Nanotechnology Commons, Other Pharmacy and Pharmaceutical Sciences Commons, and the Pharmaceutics and Drug Design Commons

\section{Recommended Citation}

Ignjatović N, Uskoković V, Ajduković Z, Uskoković D. Multifunctional hydroxyapatite and poly(D,L-lactide-co-glycolide) nanoparticles for the local delivery of cholecalciferol. Mater Sci Eng C Mater Biol Appl. 2013;33(2):943-950. doi:10.1016/ j.msec.2012.11.026. 


\section{Multifunctional Hydroxyapatite and Poly(D,L-Lactide-co-Glycolide) Nanoparticles for the Local Delivery of Cholecalciferol}

\section{Comments}

NOTICE: this is the author's version of a work that was accepted for publication in Materials Science \& Engineering C, Materials for Biological Applications. Changes resulting from the publishing process, such as peer review, editing, corrections, structural formatting, and other quality control mechanisms may not be reflected in this document. Changes may have been made to this work since it was submitted for publication. A definitive version was subsequently published in Materials Science \& Engineering C, Materials for Biological Applications, volume 33, issue 2, in 2013. DOI: 10.1016/j.msec.2012.11.026

The Creative Commons license below applies only to this version of the article.

\section{Creative Commons License}

\section{(c) (1) $\Theta \Theta$}

This work is licensed under a Creative Commons Attribution-Noncommercial-No Derivative Works 4.0 License.

\section{Copyright}

Elsevier 


\section{Keywords}

Multifunctional nano materials; Cholecalciferol; HAp; PLGA; Osteogenesis

(C) 2012 Elsevier B.V. All rights reserved.

*Corresponding author: dragan.uskokovic@itn.sanu.ac.rs (D. Uskoković). 


\section{Introduction}

Synthetic calcium phosphates, particularly calcium hydroxyapatite (HAp), are suitable candidates for a broad range of applications in biomedicine, from bone reconstruction to cancer therapies $[1,2]$. Bioresorbable polymers with comparatively slow degradation times in physiological conditions are, on the other hand, viable carriers of hydrophobic drugs, difficult to deliver by oral means, and are therefore the focus of study of numerous research groups in the drug delivery field [3,4].

The design of particulate platforms for controlled drug delivery is of particular interest for the biomedical community [5]. The current attempts to engineer efficient local and targeted drug release agents are mainly focused on nanoparticulate systems [6,7]. An interest in the applications of nanoparticles of calcium phosphates as carriers in targeted and controlled drug delivery and tissue engineering is rapidly growing [8]. HAp nanoparticles have so far been used as carriers for different pharmaceutically active components in controlled drug and gene delivery $[9,10]$. At the same time, a significant improvement of the processes of bone defect reconstruction has been achieved owing to the use of nanoparticulate systems based on HAp [9].

Multifunctional nanoparticulate systems based on HAp coated with drug-loaded bioresorbable polymers make up a separate group of controlled drug delivery systems in bone tissue engineering. While comparatively slow bioresorption of the polymer enables sustained drug release, HAp particles may act as active fillers of the bony defect. One such concept has been applied in the design of HAp nanoparticles for the local delivery of tigecycline in the treatment of osteomyelitis [10]. Sonochemical homogenous precipitation has been used for the controlled synthesis of multifunctional core-shell nanospheres composed of a bioresorbable polymer and HAp for the controlled delivery of clindamycin [11].

New strategies in the synthesis of multifunctional nanoparticles may lead to creation of orally deliverable, injectable or surgically implantable platforms as carriers of both diagnostic and therapeutic agents [12]. Precipitation techniques and membrane dialysis have helped create nanoparticulate systems for combined targeted and controlled drug delivery, allowing for their simultaneous diagnostic and therapeutic efficacy [13,14]. In this study, we have used precipitation chemistry to prepare multifunctional nanoparticulate systems for: (a) both rapid and sustained local delivery of cholecalciferol; and (b) the secondary osteoconductive effect of the defect-filling HAp carrier itself.

Cholecalciferol, an important regulator of concentrations of calcium and phosphate ions in blood serum, plays a critical role in skeletal homeostasis by controlling bone metabolism and regulating osteoblast differentiation, proliferation, apoptosis and expression of specific bone proteins and growth factors in the newly forming bone tissue $[15,16]$. Two types of nanoparticulate powders with controlled particle shapes, sizes and properties were prepared in this study: HAp particles as nanocarriers of cholecalciferol $\left(\mathrm{HAp} / \mathrm{D}_{3}\right)$, and HAp nanoparticles coated with cholecalciferol-loaded poly $(\mathrm{D}, \mathrm{L})$-lactide-co-glycolide $\left(\mathrm{HAp} / \mathrm{D}_{3} /\right.$ PLGA). Their synthesis was complemented with physicochemical characterization of 
structure and properties as well as the evaluation of their effect on osteoblastic cells and the regeneration of artificially made bone defects in vivo.

\section{Experimental}

\subsection{Synthesis of materials}

Aqueous calcium nitrate $\left(\mathrm{Ca}\left(\mathrm{NO}_{3}\right)_{2}\right)$ solution $(150 \mathrm{ml} ; 26.6 \mathrm{wt}$. \%) was added to the solution of ammonium phosphate $\left(\left(\mathrm{NH}_{4}\right)_{3} \mathrm{PO}_{4}\right)\left(7 \mathrm{ml} \mathrm{H}_{3} \mathrm{PO}_{4}+165 \mathrm{ml} \mathrm{NH}_{4} \mathrm{OH}+228 \mathrm{ml} \mathrm{H}_{2} \mathrm{O}\right)$ at 50

${ }^{\circ} \mathrm{C}$ over the period of 60 minutes, while stirring at the rate of $100 \mathrm{rpm}$. The solution was then subjected to heat treatment for 60 minutes at $100{ }^{\circ} \mathrm{C}[9,17]$. The resulting gel was dried at room temperature in a vacuum drier for $72 \mathrm{~h}$, after which the final product - HAp powder was obtained.

Cholecalciferol (crystalline 99+\%, Acros Organics) dissolved in acetone (0.4 wt.\%) was mixed with the HAp gel in the 2:8 mass ratio while stirring with a magnetic stirrer at 700 rpm. Distilled water was added drop-wise to the mixture of cholecalciferol and HAp, while stirring at 21,000 rpm (Ultra-Turrax T25, IKA, Germany). The resulting mixture was then centrifuged at $5000 \mathrm{rpm}$ and $5{ }^{\circ} \mathrm{C}$ for $1 \mathrm{~h}$ (Hettich Universal 320R). The obtained powder was subjected to frozen vacuum drying at -10 to $-60^{\circ} \mathrm{C}$, under pressures between 0.37 and 0.1 mbar over the periods between 1 and $8 \mathrm{~h}$ (Christ Alpha 1-2/LD Plus). The obtained product was the powder composed of cholecalciferol-coated HAp nanoparticles $\left(\mathrm{HAp} / \mathrm{D}_{3}\right)$. PLGA (50:50, Sigma, USA) and cholecalciferol dissolved in acetone were mixed with the HAp gel in the mass ratio of 3:2:8, respectively. The obtained mixture of cholecalciferol, PLGA and the HAp gel was slowly poured into 0.1 vol $\%$ water solution of poloxamer 188 (polyethylene-polypropylene glycol) at the speed of 21,000 rpm for one hour. The obtained mixture was then centrifuged at $500 \mathrm{rpm}$ and $5{ }^{\circ} \mathrm{C}$ for $1 \mathrm{~h}$, and the obtained powder was subjected to frozen vacuum drying at -10 to $-60{ }^{\circ} \mathrm{C}$, and pressures from 0.37 mbar to 0.1 mbar for 1 to $8 \mathrm{~h}$. The obtained product was the powder composed of HAp nanoparticles coated with cholecalciferol-loaded poly(D,L)-lactide-co-glycolide (HAp/ $\left.\mathrm{D}_{3} / \mathrm{PLGA}\right)$.

\subsection{Characterization of the products}

Roentgen structural analysis (XRD) was performed on a Philips PW-1050 diffractometer with $\mathrm{Ni}$-filtered $\mathrm{Cu}_{\mathrm{Ka}}$ radiation. The scanning step was $0.02^{\circ}$. Infrared spectroscopy (FTIR) was done on a Bomem MB 100 (Hartmann \& Braun) spectrometer using the $\mathrm{KBr}$ technique in the spectral range from 400 to $4000 \mathrm{~cm}^{-1}$. The spectral resolution was $4 \mathrm{~cm}^{-1}$. The fieldemission scanning electron microscopy (FE-SEM) measurements were performed on a SUPRA 35 VP Carl Zeiss microscope. Electrokinetic parameters of the suspensions of synthesized particles were analyzed using a Zeta-Sizer Nano (Malvern Instruments Ltd.) in distilled water and $\mathrm{pH}$ 6.5. The particle size distribution (PSD) was measured on $10 \mathrm{mg} / \mathrm{ml}$ of powders dispersed in water using a Mastersizer 2000 (Malvern Instruments Ltd.) and a HydroS dispersion unit for liquid dispersants.

\subsection{Cell culture}

Mouse calvarial preosteoblastic cell line, MC3T3-E1 subclone 4, was purchased from American Tissue Culture Collection (ATCC, Rockville, MD). MC3T3-E1 cells were 
cultured in Alpha Minimum Essential Medium (a-MEM; Gibco) supplemented with 10\% fetal bovine serum (FBS, Invitrogen) and no ascorbic acid (AA). The medium was replaced every $48 \mathrm{~h}$, and the cultures were incubated at $37{ }^{\circ} \mathrm{C}$ in a humidified atmosphere containing $5 \% \mathrm{CO}_{2}$. Every 7 days, the cells were detached from the surface of the $75 \mathrm{~cm}^{2}$ cell culture flask (Greiner Bio-One) using $0.25 \mathrm{wt} . \%$ trypsin, washed, centrifuged (1000 rpm $\times 3 \mathrm{~min}$ ), resuspended in $10 \mathrm{ml}$ of the cell culture medium and subcultured in 1:7 volume ratio. Cell passages 6-12 were used for the experiments reported hereby. The cultures were regularly examined under an optical microscope to monitor growth and possible contamination.

MC3T3-E1 cells were seeded on glass cover slips placed in 24 well plates and $500 \mu \mathrm{l}$ of aMEM supplemented with $10 \%$ fetal bovine serum (FBS, Invitrogen) and no AA at the density of $6 \times 10^{4}$ cells per well. After 5 days of incubation, nearly confluent cells were treated with a-MEM containing $50 \mu \mathrm{g} / \mathrm{ml} \mathrm{AA}$ as the mineralization inductor. At the same time, $2 \mathrm{mg} / \mathrm{cm}^{2}$ of $\mathrm{HAp}, \mathrm{HAp} / \mathrm{D}_{3}$ and $\mathrm{HAp} / \mathrm{D}_{3} / \mathrm{PLGA}$ were added to the cells, separately. The subsequent incubation lasted for 7 days, during which a-MEM supplemented with 50 $\mu \mathrm{g} / \mathrm{ml}$ AA was replenished every $48 \mathrm{~h}$. After the given period, one portion of cells was fixed for $15 \mathrm{~min}$ in $3.7 \mathrm{wt} . \%$ paraformaldehyde at room temperature and then stained for f-actin and nucleus using phalloidin-tetramethylrhodamine (AlexaFluor 555, Invitrogen) and 4',6diamidino-2-phenylindole dihydrochloride nuclear counterstain (DAPI, Invitrogen), following a previously described protocol [18].

The cover slips containing the fixed and stained cells were mounted onto glass slides using hard set vectashield and nail hardener and were subsequently imaged under a confocal laser scanning microscope-C1si (UCSF Nikon Imaging Center) at 100× magnification in oil.

\subsection{In vivo tests}

Bone regeneration tests were conducted on 36 rats, Wister species. The animals were introduced to the experiment when they reached the age of six to eight weeks. They were divided into two groups: one group ( 9 animals) was the control group and the other one was the experimental group ( 27 animals). The experimental group was treated with glucocorticoids in order to induce osteoporosis. The animals were given glucocorticoidsmetilprednisolone Na-succinate (Lemod-Solu, Hemofarm, Vršac, Srbija) dosed $2 \mathrm{mg}$ per kg of body mass and dexamethasone-Na-phosphate (Dexason, ICN Galenika, Belgrade, Serbia) dosed $0.2 \mathrm{mg}$ per kg of body mass. These substances were applied intramuscularly and alternately in the course of 12 weeks, so that each substance was applied every other day. During those 12 weeks, the control group of animals received saline intramuscularly on a daily basis. After the 12 week period the animals in the control group did not exhibit any defects, whereas the animals from the experimental group had defects introduced on the left side of the mandible alveolar bone, in the region between the medial line and foramen mentale. The defect was created using a sterile steel borer, $1.6 \mathrm{~mm}$ in diameter and $1.8 \mathrm{~mm}$ in length. The animals had been prepared for this intervention by the application of diazepam (Bensendin, ICN Galenika, Belgrade, Serbia) and were subsequently anesthetized with ketamine hydrochloride USP (Ketalar, Rotexmedica Gmbh, Trittau, Germany). The experimental group was divided into three subgroups with nine animals each. Rats in the first group had HAp powder implanted into the defect; rats in the second group had HAp/D3 
powder implanted into the defect; rats in the third group had HAp/D3/PLGA powder implanted into the defect. The powders delivered to of all three experimental subgroups had previously been mixed with saline $(0.9 \% \mathrm{NaCl}$ solution) in the $2: 1$ ratio. The animals were sacrificed 6 and 24 weeks after the intervention because previous studies have shown that the best results can be expected in this period [9]. After the mentioned time interval, decalcified samples of the alveolar bone were taken, and after dehydration in a series of alcohol, paraffin blocks were made, out of which we took fragments with $10 \mu \mathrm{m}$ in width, coloured according to H\&E method for pathohistological analysis [9]. The procedures involving experimental animals were done in accordance with the Guidelines for Work with Experimental Animals adopted by the Ethics Committee of the Faculty of Medicine, University of Niš, Serbia (No 01-890-3/2011).

\section{Results and discussion}

Fig. 1 shows the diffractograms of PLGA, HAp, cholecalciferol, HAp/D 3 and HAp/ $\mathrm{D}_{3} /$ PLGA. No diffraction peaks are visible on the diffractogram of PLGA, as expected due to the amorphous nature of this polymer. The most intensive peaks of HAp (International Center for Diffraction Data, JCPDS file No. 09-432) are found at $31.8^{\circ}\left(\begin{array}{lll}2 & 1 & 1\end{array}\right), 32.2^{\circ}\left(\begin{array}{ll}1 & 1\end{array}\right)$, $32.9^{\circ}\left(\begin{array}{lll}3 & 0 & 0\end{array}\right), 25.9^{\circ}\left(\begin{array}{lll}0 & 0 & 2\end{array}\right)$ and $49.5^{\circ}\left(\begin{array}{lll}2 & 1 & 3\end{array}\right)$. It is likely that the given phase is calciumdeficient HAp, as in accordance with the previously published results $[17,19]$. The mean crystallite size (D) of the powders calculated from the half-width $\left(\beta_{1 / 2}\right)$ of the XRD reflection of the (002) plane $\left(2 \theta=25.9^{\circ}\right)$ using the Scherrer equation was $12.5 \mathrm{~nm}$. The degree of crystallinity of HAp could be facilely determined from its XRD pattern [20]. Similar in appearance to that obtained by different researchers $[17,19,21]$, the diffractogram shown in Fig. 1 corresponds mainly to poorly crystalline HAp. This result was expected bearing in mind that the HAp gel was synthesized by precipitation at $100{ }^{\circ} \mathrm{C}$ and $\mathrm{pH} 12$; HAp synthesis at this temperature leads to poorly crystalline HAp [21]. Hand-in-hand with poor crystallinity of HAp powders typically goes a reduction in stoichiometric $\mathrm{Ca} / \mathrm{P}$ ratios towards values lower than 1.67 , as observed by others [22]. Thus obtained poorly crystalline form of HAp bears resemblance to bone apatite and can be hypothesized to present a more osteogenic crystalline form compared to highly structured apatite obtainable by annealing at elevated temperatures. The high crystalline form of HAp, distinguished by narrow and sharp diffraction peaks, was obtained using a similar synthesis procedure, but involving also additional calcination at high temperatures $[17,21,23]$.

The diffractogram of cholecalciferol with the most intensive peak at $18.2^{\circ}$ suggests its existence in a crystalline form and is in agreement with the XRD research reported elsewhere [24]. The diffractogram of $\mathrm{HAp} / \mathrm{D}_{3}$ powder exhibits the diffraction peaks typical for the two phases separately, confirming their mutual presence in it. Comparatively broader diffraction peaks discernable in the XRD pattern of $\mathrm{HAp} / \mathrm{D}_{3} / \mathrm{PLGA}$ indicate that the structure of the organic component in the composite sample exhibits a lesser degree of ordering compared to its pure crystalline state.

The electrokinetic parameters of materials in aqueous suspension indicate their stability in suspended state and thus suggest the possibility for their therapeutic application by injection using water as the dispersion medium. Generally, zeta potential (ZP) values of 0 to $\pm 15 \mathrm{mV}$ 
indicate sols prone to flocculation and aggregation, whereas absolute ZP values higher than $15 \mathrm{mV}$ are characteristic for stable and aggregation-resistant particles [25,26]. Table 1 shows the values of $\mathrm{ZP}$, mobility and conductivity of particles in the aqueous medium. Fig. 2 shows the distribution of the ZP values for the synthesized particles of HAp, HAp/D3 and $\mathrm{HAp} / \mathrm{D} 3 / \mathrm{PLGA}$ in distilled water at $25^{\circ} \mathrm{C}$ and $\mathrm{pH}$ 6.5. $\mathrm{ZP}$ values are in the range of -7.5 $\mathrm{mV}$ for HAp to $-23.6 \mathrm{mV}$ for $\mathrm{HAp} / \mathrm{D} 3$ to $-33.1 \mathrm{mV}$ for $\mathrm{HAp} / \mathrm{D}_{3} / \mathrm{PLGA}$. Electrophoretic mobility and conductivity values also follow the decreasing trend in the sequence $\mathrm{HAp}>\mathrm{HAp} / \mathrm{D}_{3}>\mathrm{HAp} / \mathrm{D} 3 / \mathrm{PLGA}$ and confirm the different electrodynamic nature of the particle surfaces. The process of coating of HAp nanoparticles as well as their subjugation to encapsulation of hydrophobic drugs can be confirmed by following the corresponding changes in electrokinetic parameters, particularly ZP [27]. The results shown in Table 1 indicate a progressive increase in the absolute values of $\mathrm{ZP}$ as the core HAp particles are first coated with cholecalciferol and then with cholecalciferol-loaded poly $(\mathrm{D}, \mathrm{L})$-lactide-coglycolide. Whereas ZP of HAp particles is comparatively low, in the order of 0 to $-10 \mathrm{mV}$ [28], both cholecalciferol and poly(D,L)-lactide-co-glycolide are typified by significantly more negative $\mathrm{ZP}$ values, approaching $-40 \mathrm{mV}$ at the physiological $\mathrm{pH}$ for the latter [29]. To further confirm this observation, FT-IR and FE-SEM examination were performed next.

FT-IR spectra of cholecalciferol, HAp, HAp/D 3 and HAp/D3/PLGA, as well as the magnified spectrum in Region A are shown in Fig. 3. The FT-IR spectrum of HAp is defined by a doublet with maxima at 1035 and $1092 \mathrm{~cm}^{-1}$ and by a triplet with most pronounced maxima at 561 and $603 \mathrm{~cm}^{-1}$, all of which are due to vibrations of the phosphate group. The bands with maxima at 632 and $3567 \mathrm{~cm}^{-1}$ are caused by the vibrations of the hydroxyl group in the crystal lattice of HAp [30]. Cholecalciferol is typified by the $\mathrm{CH}_{3}$ asymmetric stretching mode and the $\mathrm{CH}_{2}$ symmetric stretching mode at 2943 and 2875 $\mathrm{cm}^{-1}$, respectively [31,32], the two bands that are observable in our spectrum of the vitamin too. The spectrum of $\mathrm{HAp} / \mathrm{D}_{3}$ exhibits the most intensive bands of both HAp and cholecalciferol, indicating that the synthesized material is composed of HAp and cholecalciferol, as in accordance with the XRD results. The appearance of new bands is also noticed, especially in the region marked by A. In comparison with the X-ray diffractograms of $\mathrm{HAp} / \mathrm{D}_{3} / \mathrm{PLGA}$, its FT-IR spectrum shows the specific bands of PLGA (the most significant one being the stretching $\mathrm{C}=\mathrm{O}$ vibrations at around $1760 \mathrm{~cm}^{-1}[33]$ ), as well as the presence of the bands of HAp and cholecalciferol.

Phosphate groups in calcium phosphates can form hydrogen bonds in contact with vitamins from the group D [32]. The appearance of new and weak bands in spectra of $\mathrm{HAp} / \mathrm{D}_{3}$ and $\mathrm{HAp} / \mathrm{D}_{3} / \mathrm{PLGA}$, in the range of $3650-3690 \mathrm{~cm}^{-1}$, may indicate the formation of the surface $\mathrm{P}-\mathrm{O}-\mathrm{H}$ groups originating from the protonation of the surface $\mathrm{PO}_{4}^{3-}$ groups of HAp [34]. The surface $\mathrm{PO}_{4}^{3-}$ groups from HAp are prone to forming hydrogen bonds in the close presence of hydroxyl groups [35], being the basic mechanism by which hydrogen bonds between HAp and cholecalciferol or PLGA form. Fig. $3 \mathrm{~b}$ shows the magnified spectra of the materials in the region $3620-3750 \mathrm{~cm}^{-1}$ where the appearance of new bands reflecting the formation of hydrogen bonds between HAp and other constituents that make up the particles can be observed. The weak bands at $3689 \mathrm{~cm}^{-1}, 3675 \mathrm{~cm}^{-1}$ and $3648 \mathrm{~cm}^{-1}$ are assigned to hydrogen bonding to the surface P-OH groups of HAp. The mechanism for the formation of 
hydrogen bonds in $\mathrm{HAp} / \mathrm{D}_{3} / \mathrm{PLGA}$ is more complex because the protonation of the surface groups of HAp most likely does not originate solely from cholecalciferol, but also from PLGA. The appearance of new and weak bands in HAp/polylactide nanocomposites in the range of $3650-3690 \mathrm{~cm}^{-1}$ has thus been explained by the formation of hydrogen bonds between the polymer and HAp [36]. The structure of cholecalciferol $(9,10-$

Secocholesta-5,7,10(19)-trien-3beta-ol) suggests the existence of spatially interconnected $\mathrm{H}$ and $-\mathrm{OH}$ groups, while the structure of PLGA has spatially connected $\mathrm{O}$ and $-\mathrm{H}$ groups in the polymer chain available to participate in the formation of hydrogen bonds with the surface groups of HAp.

FE-SEM images of HAp, HAp/D 3 and HAp/ $\mathrm{D}_{3} / \mathrm{PLGA}$ are shown in Fig. 4. The particles of HAp display a rod-like morphology (Fig. 4a). After the coating of HAp with cholecalciferol (Fig. 4b), more round particle shapes were obtained compared to pure HAp (Fig. 4a). $\mathrm{HAp} / \mathrm{D}_{3} / \mathrm{PLGA}$ particles had spherical morphologies too (Fig. 4c). Additional processing in the centrifugal field of the suspension of nanoparticles of HAp coated with PLGA has previously led to the formation of spherical morphologies [37,38]; accordingly, since we used centrifugal processing too in the processing method reported herein, spherical morphologies were obtained as well.

Aqueous suspensions of the particles of HAp, HAp/D $\mathrm{D}_{3}$ and HAp/ $/ \mathrm{D}_{3} / \mathrm{PLGA}$ were analyzed with the aim of establishing their size distributions. Fig. 5 shows the size distributions for the suspended particles of HAp, HAp/D3 and HAp/D3/PLGA powders in distilled water. The particle sizes for all the analyzed powders range from $30 \mathrm{~nm}$ to $1 \mu \mathrm{m}$. HAp particles (Fig. 5a) have $\mathrm{d} 10=35 \mathrm{~nm}$; d50=65 nm and d90=124 nm. HAp/D3 system has a distribution with the parameters $\mathrm{d} 10=36 \mathrm{~nm}, \mathrm{~d} 50=68 \mathrm{~nm}$ and $\mathrm{d} 90=143 \mathrm{~nm}$, and HAp/D3/PLGA d10=37 $\mathrm{nm}, \mathrm{d} 50=71 \mathrm{~nm}$ and d90=168 nm (Fig. 5b-c). A general trend towards increasing the average particle size (d50) with the addition of a new component can be noticed; hence, the sequence $\mathrm{HAp}>\mathrm{HAp} / \mathrm{D}_{3}>\mathrm{HAp} / \mathrm{D}_{3} / \mathrm{PLGA}$ with respect to $\mathrm{d} 50, \mathrm{~d} 10$ and $\mathrm{d} 90$. The largest particles of $1.5 \mu \mathrm{m}$ were detected in $\mathrm{HAp} / \mathrm{D}_{3} / \mathrm{PLGA}$ and comprised $0.01 \%$ of the overall particle number. The smallest ones, measuring $22 \mathrm{~nm}$ in size, were detected in HAp $(0.5 \%$ of the total particle count).

A consistent increase in the particle size (HAp $\left.>\mathrm{HAp} / \mathrm{D}_{3}>\mathrm{HAp} / \mathrm{D}_{3} / \mathrm{PLGA}\right)$ is expected as the result of the coating process. The coating of HAp particles with cholecalciferol thus leads to an increase in their size, while coating of HAp particles with a polymer in which the vitamin was immobilized leads to a further increase in size. The procedure for coating HAp particles with cholecalciferol (or cholecalciferol-loaded PLGA) takes place by adding a non-solvent to induce the precipitation of cholecalciferol (or cholecalciferol-loaded PLGA) with the existing HAp particles acting as sedimentation centres. In our earlier research, we examined the possibility of coating the microparticles of HAp with PLGA by the solvent/non-solvent method in which HAp particles were the sedimentation centres for PLGA [23]. For the abovementioned reasons, the size increase of particles after coating HAp with cholecalciferol or the polymer is expected. The thickness of the coated layer chiefly depends on the mass proportion of cholecalciferol and PLGA relative to the quantity of the initial HAp particles. 
Fig. 6 displays the confocal optical images of osteoblastic cells following incubation with the three types of particles prepared and analyzed in this study, fluorescently counterstained for nucleus (blue) and f-actin cytoskeletal microfilaments (red). It is apparent that while the viability of cells incubated in the presence of either pure HAp or HAp/ $\mathrm{D}_{3} / \mathrm{PLGA}$ does not show any diminishment nor the healthy morphology of cells seems to be lost when compared to the control, cells incubated with $\mathrm{HAp} / \mathrm{D}_{3}$ appear morphologically deformed, necrotic and exhibiting a significantly lower cell density in comparison with the control sample. An extensive amount of cholecalciferol released into the cell medium has thus been shown to have a drastic effect on reducing the cell viability. A possible explanation for this effect may relate to the already observed ability of calcitriol, the bioactive form of vitamin $\mathrm{D}_{3}$ derivative, to force the release of RANKL, a tumor necrosis factor cytokine, which stops the bone formation process and activates osteoclasts, the bone-resorbing cells [39].

Having a role in mitosis and differentiation of osteoblasts, it was natural to expect that cholecalciferol would have an effect on osteogenesis. So far, no results of in vivo analyses related to multifunctional nanoparticulate systems for local delivery of the vitamins from the D group could be found in literature. Figs. 7 and 8 show histopathological images of the mandible bone 6 and 24 weeks after the implantation of different materials has been carried out, respectively. Fig. 7a of the control group, in which no defect has been made, shows mature bone as well as blood vessels and Haversian canals. The new bone with remains of ossification centres can be seen in Fig. 7b. Fig. 7c shows numerous ossification centres with giant cells which are not distributed in a palisade, but scattered in a disordered manner. Specific forms of ossification distributed in islet-like formations, the creation of young bone, i.e., accelerated activity of osteogenesis cells, cement lines and mature bone can be seen in Fig. 7d.

Compared to the cortical bone of the control group 24 weeks after the implantation, healing in the presence of any of the materials synthesized within this study seems to be facilitated. After the defects have been filled with HAp, the resorption of the implanted material and its replacement by the newly formed bone are observed (Fig. 7b). After the implantation of the $\mathrm{HAp} / \mathrm{D}_{3}$, patches of poorly mineralized new hard tissue become visible too (Fig. $7 \mathrm{c}$ ).

Six weeks after the reconstruction of the defect with HAp/D $/$ PLGA (Fig. 8d), newly formed bone around the defect was visible as well as cement lines and the blood supply. In the centre of the defect, a piece of the implanted material with ray-like zones where the material was replaced with the newly formed, poorly mineralized bone tissue can be observed. Intensive angiogenesis is present, as well as vascularization and osteogenesis. Vascularization is essential for successful regeneration of bone, as confirmed in other studies [40].

Twenty-four weeks after the reconstruction of the bone defect, the formation of new bone tissue has additionally improved after the application of all types of materials. After the reconstruction with $\mathrm{HAp} / \mathrm{D}_{3}$ (Fig. 8c), numerous ossification centres were visible, along with the giant cells. The transition of young bone tissue into mature tissue is observable in all the reconstructed defects. Following the period of intensive angiogenesis and vascularization (Fig. 7d), the most intensive differentiation and osteogenesis were seen when 
HAp/D3/PLGA was used as the filler (Fig. 8d). In the central area of the image, a broad line of young bone tissue transforming into mature tissue is visible, interspersed with several islet-like ossification centres. Moving from right to left in Fig. 8d, represented is the transition from young bone to mature bone.

To become bioactive, cholecalciferol has to be hydroxylated twice: first in the liver and then by the convoluted tubule cells of the kidney. Its direct delivery to cells in its raw, naturally found form and in overly high fluxes apparently has a negative effect on osteoblastic cells which undergo necrosis under such conditions. The positive effects on the orthodontic stability of teeth in the treatment of parodontopathy has been noted previously upon the local delivery of calcitriol, that is, 1,25-dihydroxycholecalciferol, the bioactive form of cholecalciferol [41,42]. In those studies, the activation effect of vitamin D on monocytes was shown, as well as the stimulating effect on cell-mediated immunity with the suppression of lymphocytic proliferation [41]. The local use of calcitriol significantly increased the activity of osteoblasts, which resulted in an improved recovery of alveolar bone [42]. In the future studies, we will extend our investigation of the local delivery of vitamin D family of compounds to calcitriol.

\section{Conclusion}

Development of a multifunctional nanoparticulate material for simultaneous (a) acceleration of natural bone regeneration and (b) sustained drug release, composed of hydroxyapatite and poly-(DL-lactide-co-glycolide), presented the subject of this study. In this work, we prepared two different osteoconductive carriers for the local delivery of cholecalciferol: pulse $\left(\mathrm{HAp} / \mathrm{D}_{3}\right)$ and sustained $\left(\mathrm{HAp} / \mathrm{D}_{3} / \mathrm{PLGA}\right)$. The fast delivery was achieved by desorption of the drug from the HAp particle surface, while the slow delivery was conditioned by the rather slow degradation of PLGA in physiological conditions. Although the former way of delivery had a highly negative effect on osteoblastic cells in vitro, it did not hinder the healing of osteoporotic bone in vivo. An important feature of these nanoparticulate carriers is their multifunctionality. Namely, after the drug has been delivered, HAp could take the role of the defect filler that is to be gradually substituted with the new bone.

\section{Acknowledgments}

The authors acknowledge Dr. Vladimir Srdić of the Faculty of Technical Sciences, University of Novi Sad for his assistance in zeta potential measurements, Dr. Saša Drmanić of the Faculty of Technology and Metallurgy, University of Belgrade, for his help in IR measurements, and Dr. S. Škapin of Jozef Stefan Institute, Slovenia, for the FE-SEM imaging. The research presented in this paper was supported by the Ministry of Education and Science of the Republic of Serbia, under project no. III45004 and the US National Health Institute grant K99-DE021416.

\section{References}

1. Hench L. J Am Ceram Soc. 1991; 74:1487-1510.

2. Vallet-Regí M, Ruiz-Hernández E. Adv Mater. 2011; 23:5177-5218. [PubMed: 22009627]

3. Naderi H, Matin M, Bahrami A. J Biomater Appl. 2011; 26:383-417. [PubMed: 21926148]

4. Gref R, Minamitake Y, Peracchia M, Trubetskoy V, Torchilin V, Langer R. Science. 1994; 263:1600-1603. [PubMed: 8128245] 
5. Kolishetti N, Dhar Sh, Valencia P, Lin L, Karnik R, Lippard S, Langer R, Farokhzad O. Proc Natl Acad Sci U S A. 2010; 107:17939-17944. [PubMed: 20921363]

6. Depan D, Misra RDK. Mater Sci Eng C Mater Biol Appl. 2012; 32:1704-1709. [PubMed: 24364981]

7. Zhang, Z.; Huang, G. J Nanotechnol. 2012. http://dx.doi.org/10.1155/2012/748909

8. Bose S, Tarafder S. Acta Biomater. 2012; 8:1401-1421. [PubMed: 22127225]

9. Ignjatović N, Ajduković Z, Savić V, Uskoković D. J Biomed Mater Res B Appl Biomater. 2010; 94:108-117. [PubMed: 20524184]

10. Ignjatović N, Ninkov P, Sabetrasekh R, Uskoković D. J Mater Sci Mater Med. 2010; 21:231-239. [PubMed: 19707858]

11. Vukomanović M, Škapin SD, Poljanšek I, Žagar E, Kralj B, Ignjatović N, Uskoković D. Colloids Surf B Biointerfaces. 2011; 82:414-421. [PubMed: 20951006]

12. Parveen S, Misra R, Sahoo S. Nanomedicine. 2012; 8:147-166. [PubMed: 21703993]

13. Li X, Qian Y, Liu T, Hu X, Zhang G, You Y, Liu Sh. Biomaterials. 2011; 32:6595-6605. [PubMed: 21663960]

14. Kim K, Kim J, Park H, Kim YS, Park K, Nam H, Lee S, Park J, Park RW, Kim IS, Choi K, Kim S, Park K, Kwon I. J Control Release. 2010; 146:219-227. [PubMed: 20403397]

15. van Driel M, Pols H, van Leeuwen J. Curr Pharm Des. 2004; 10:2535-2555. [PubMed: 15320744]

16. Jones G. Am J Clin Nutr. 2008; 88:582S-586S. [PubMed: 18689406]

17. Ignjatović NL, Liu CZ, Czernuszka JT, Uskoković DP. Acta Biomater. 2007; 3:927-935. [PubMed: 17532275]

18. Uskoković V, Lee P, Walsh L, Fischer K, Desai T. Biomaterials. 2012; 33:1663-1672. [PubMed: 22116000]

19. Caroline Victoria E, Gnanam FD. Trends Biomater Artif Organs. 2002; 16:12-14.

20. Keller L, Dollase W. J Biomed Mater Res. 2000; 49:244-249. [PubMed: 10571912]

21. Kumta P, Sfeir C, Lee D, Olton D, Choi D. Acta Biomater. 2005; 1:65-83. [PubMed: 16701781]

22. LeGeros R, Lin S, Rohanizadeh R, Mijares D, LeGeros J. J Mater Sci Mater Med. 2003; 14:201209. [PubMed: 15348465]

23. Ignjatovic N, Ajdukovic Z, Uskokovic D. J Mater Sci Mater Med. 2005; 16:621-626. [PubMed: 15965593]

24. Fei X, Heyang J, Yaping Z, Xinqiu G. Chin J Chem Eng. 2011; 19:1039-1046.

25. Xu R. Particuology. 2008; 6:112-115.

26. Uskoković, V. Dynamic light scattering and microelectrophoresis: main prospects and limitations. J Dispers Sci Technol. 2012. http://dx.doi.org/10.1080/01932691.2011.625523

27. Xu Q, Tanaka Y, Czernuszka J. Biomaterials. 2007; 28:2687-2694. [PubMed: 17331574]

28. Uskoković V, Uskoković D. J Biomed Mater Res B Appl Biomater. 2011; 96B:152-191. [PubMed: 21061364]

29. Patil Y, Panyam J. Int J Pharm. 2009; 367:195-203. [PubMed: 18940242]

30. Ignjatović N, Uskoković D. Spectroscopy. 2004; 18:553-565.

31. Morris W, Wilkie J, Jones S, Friedman L. Anal Chem. 1962; 34:381-384.

32. Toyran N, Severcan F. Spectroscopy. 2002; 16:399-408.

33. Paragkumar T, Edith D, Jean-Luc S. Appl Surf Sci. 2006; 253:2758-2764.

34. Ishikawa T, Wakamura M, Kondo S. Langmuir. 1989; 5:144-147.

35. Borum-Nicholas L, Wilson O Jr. Biomaterials. 2003; 24:3671-3679. [PubMed: 12818538]

36. Zhou, Sh; Zheng, X.; Yu, X.; Wang, J.; Weng, J.; Li, X.; Feng, B.; Yin, M. Chem Mater. 2007; 19:247-253.

37. Vukomanović M, Škapin SD, Jančar B, Maksin T, Ignjatović N, Uskoković V, Uskoković D. Colloids Surf B Biointerfaces. 2011; 82:404-413. [PubMed: 20951005]

38. Vukomanović M, Zavašnik-Bergant T, Bračko I, Radmilović V, Davor Škapin S, Ignjatović N, Uskoković D. Colloids Surf B Biointerfaces. 2011; 87:226-235. [PubMed: 21723099] 
39. Bringhurst, R.; Demay, M.; Krane, S.; Kronenberg, H. Harrison's Principles of Internal Medicine. 17. Fauci, A.; Braunwald, E.; Kasper, D.; Hauser, S.; Longo, D.; Jameson, J.; Loscalzo, J., editors. Vol. 346. McGraw-Hill; New York: 2008.

40. Das A, Botchwey E. Tissue Eng Part B Rev. 2011; 17:403-414. [PubMed: 21902609]

41. Tachi Y, Shimpuku H, Nosaka Y, Kawamura T, Shinohara M, Ueda M, Imai H, Ohura K. Life Sci. 2003; 73:3313-3321. [PubMed: 14572874]

42. Kawakami M, Takano-Yamamoto T. J Bone Miner Metab. 2004; 22:541-546. [PubMed: 15490263] 


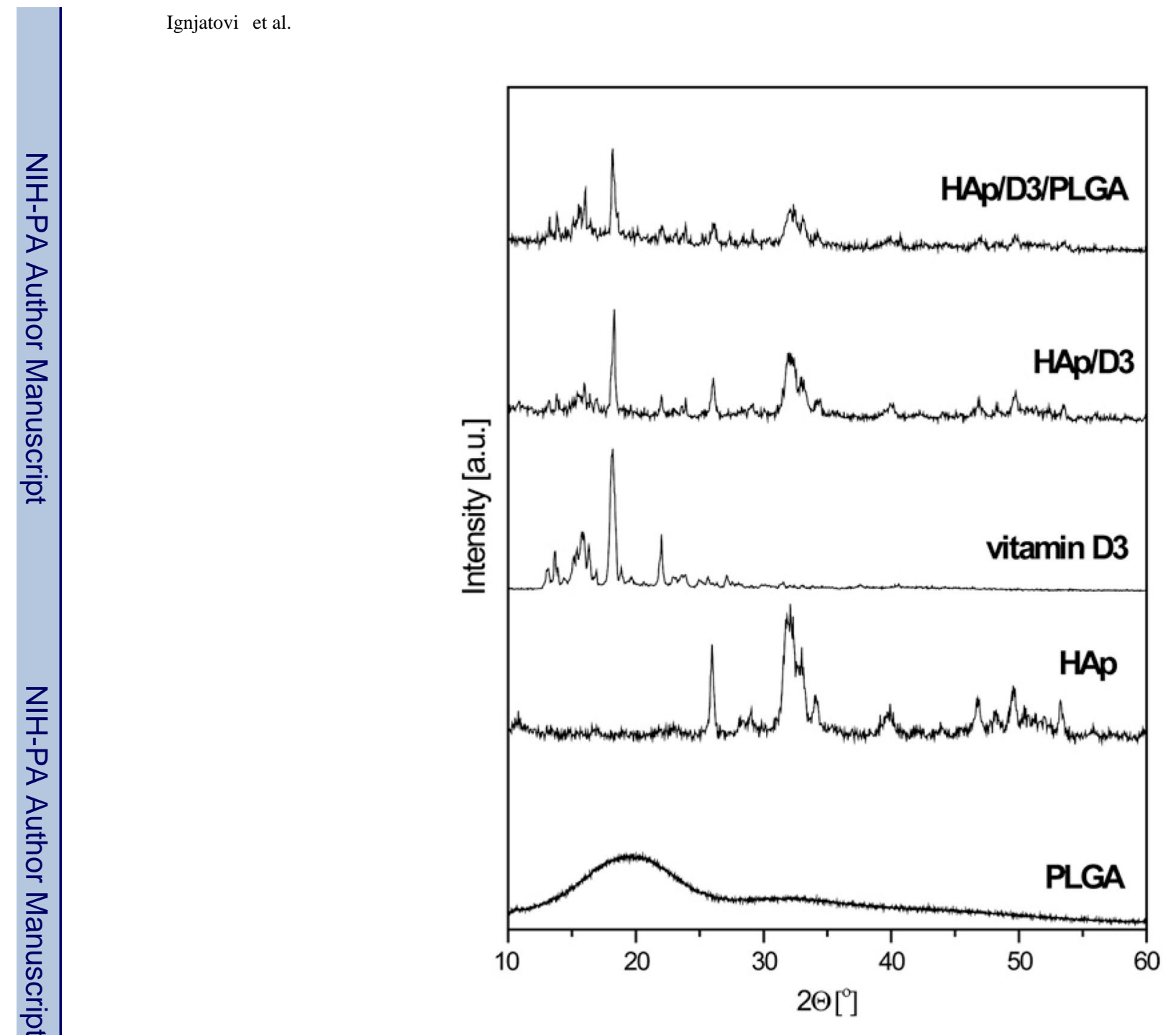

Fig. 1.

XRD diagrams of HAp, HAp/D3 and HAp/D3/PLGA. 


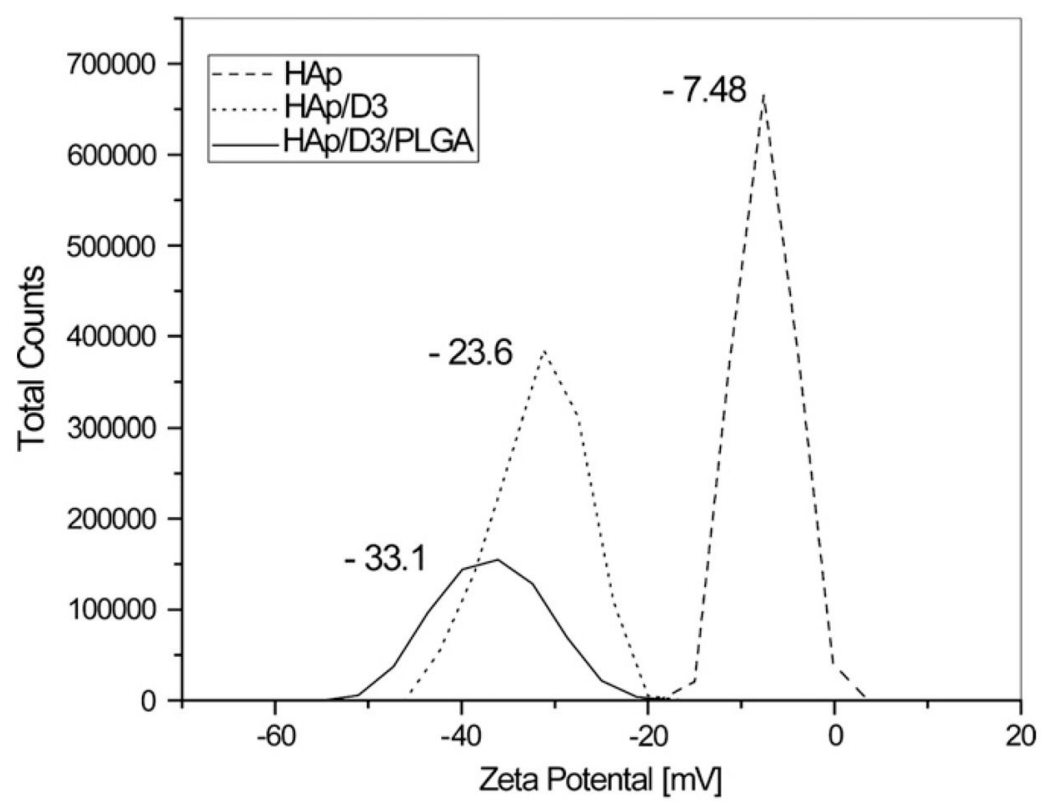

Fig. 2.

Zeta potential distribution for HAp, $\mathrm{HAp} / \mathrm{D}_{3}$ and $\mathrm{HAp} / \mathrm{D}_{3} / \mathrm{PLGA}$ particles. 

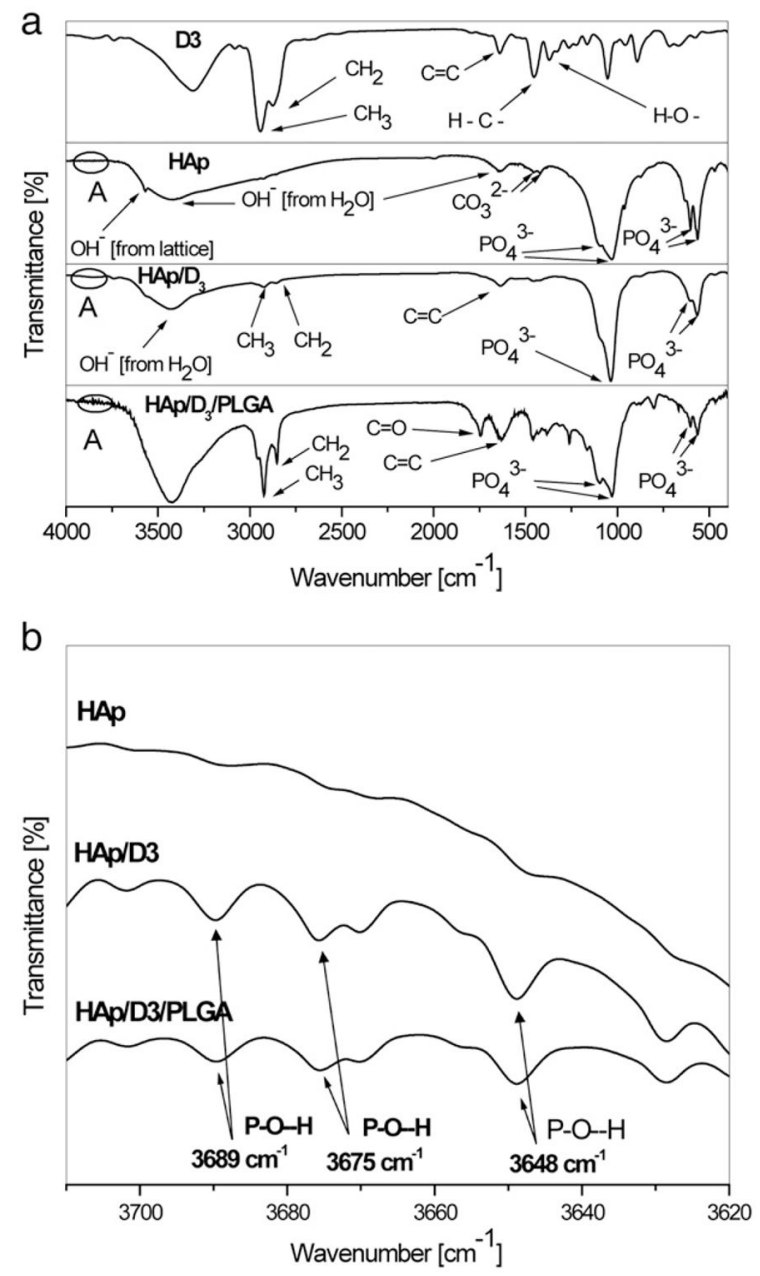

Fig. 3.

FT-IR spectra of cholecalciferol, HAp, HAp/D 3 and HAp/D $3 /$ PLGA (a), magnified spectra in Region A (b). 

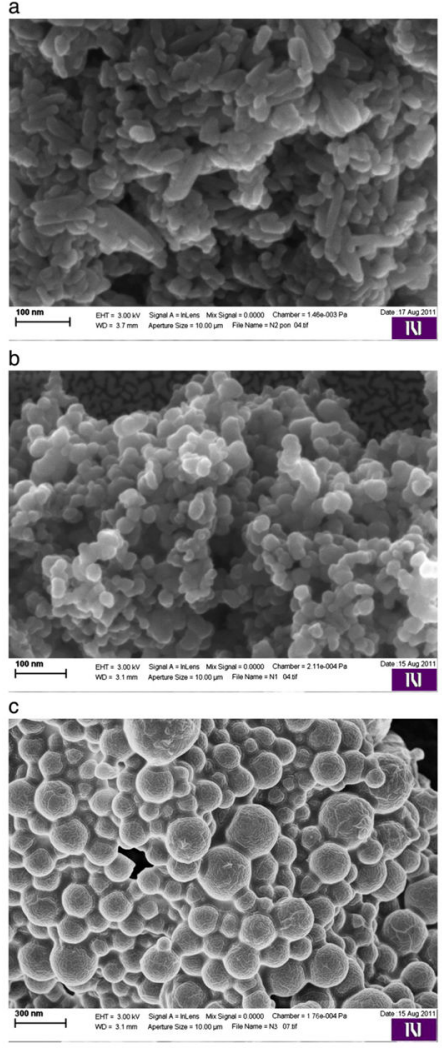

Fig. 4.

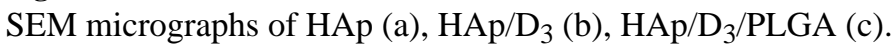



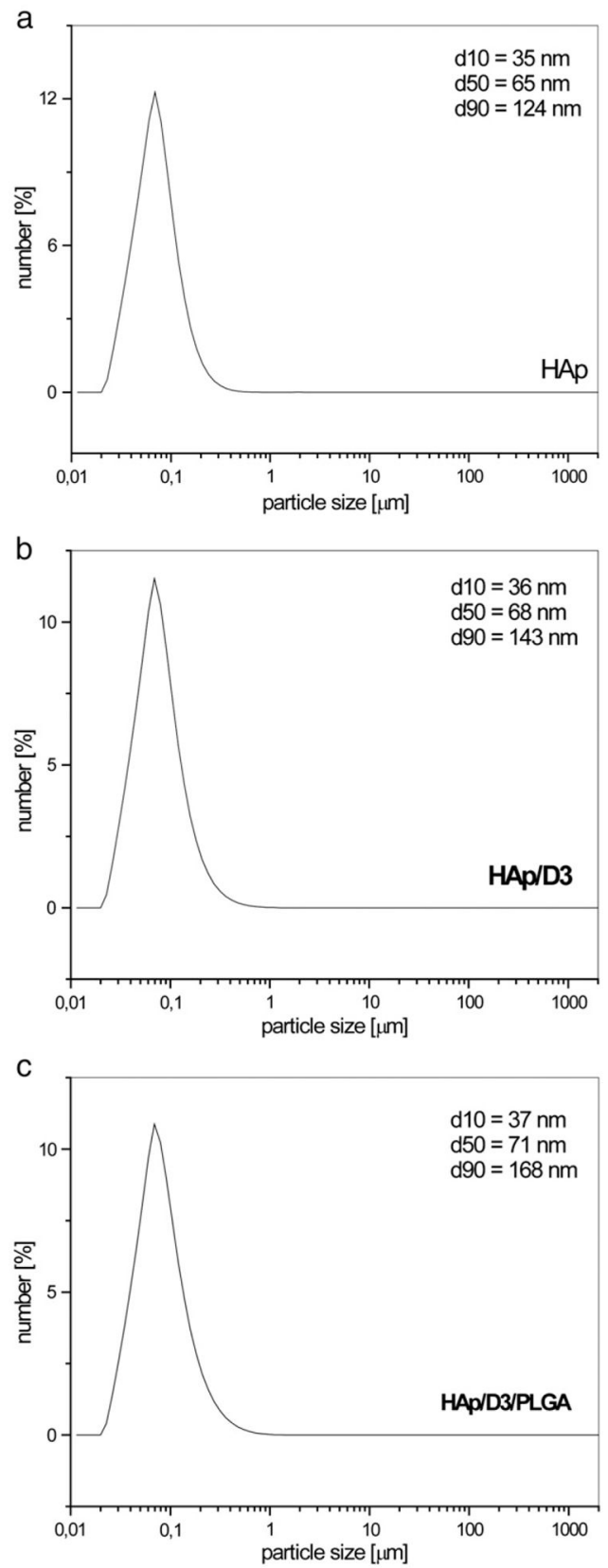

Fig. 5.

Particle size distributions of HAp (a), HAp/D $\mathrm{D}_{3}$ (b), HAp/D $/$ PLGA (c). 

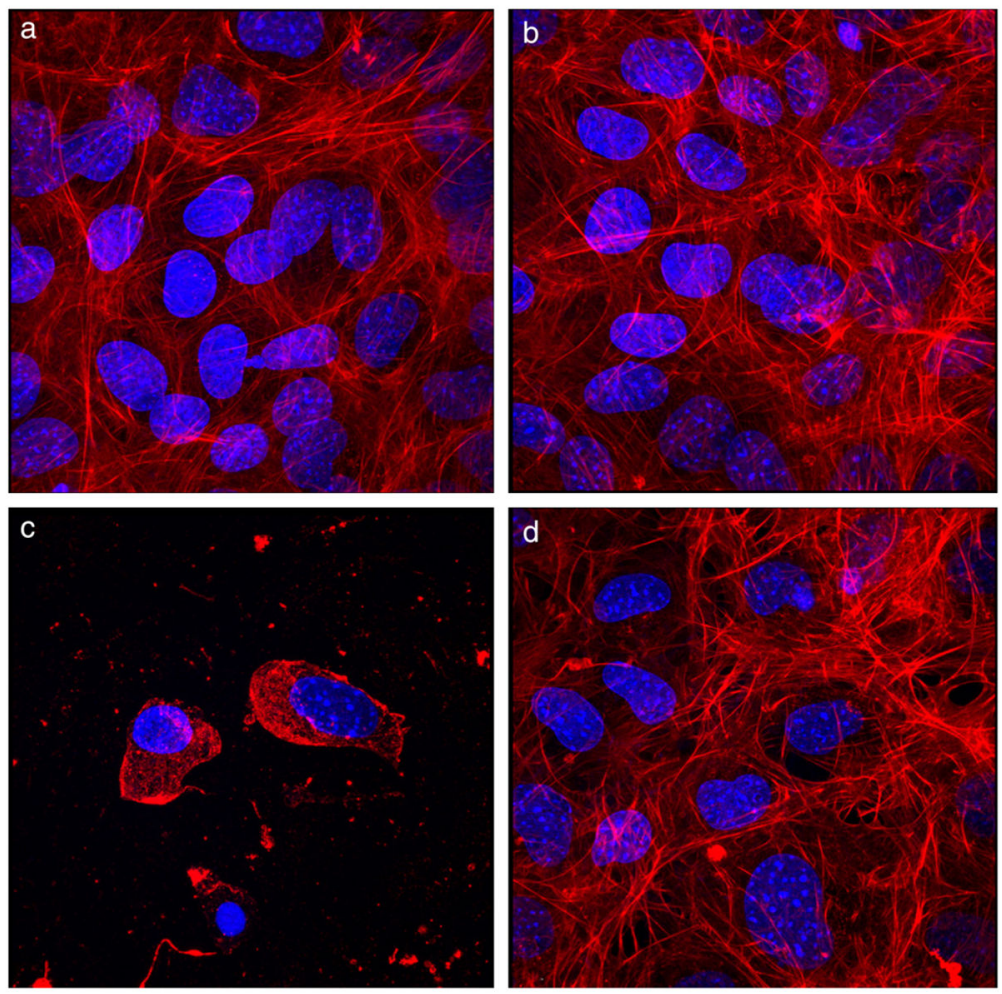

Fig. 6.

Confocal optical micrographs of osteoblastic cells incubated with no particles (a), with HAp (b), with $\mathrm{HAp} / \mathrm{D}_{3}$ (c), or with $\mathrm{HAp} / \mathrm{D}_{3} / \mathrm{PLGA}$ (d), fluorescently stained for nucleus (blue) and cytoskeletal f-actin (red) following 4 days of incubation. The size of each image is $300 \times 300 \mu \mathrm{m}$. 
a

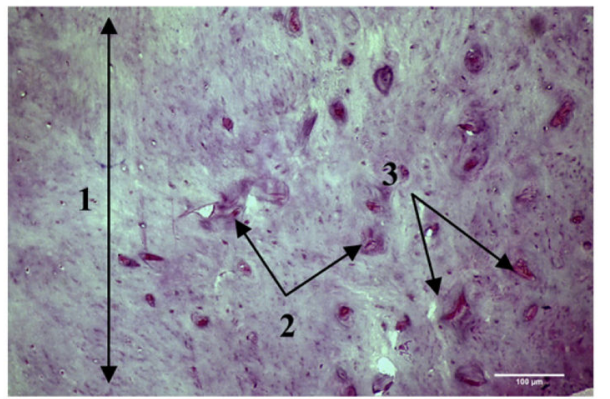

C

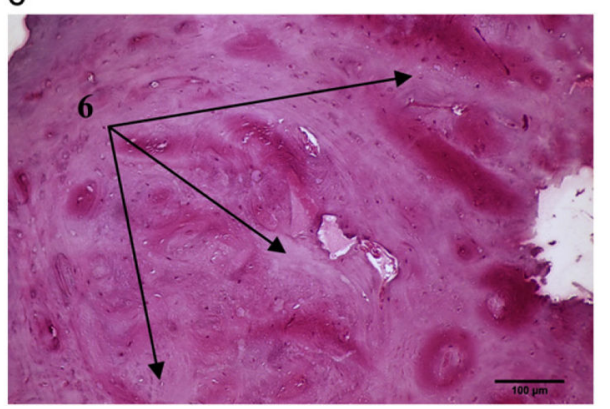

b

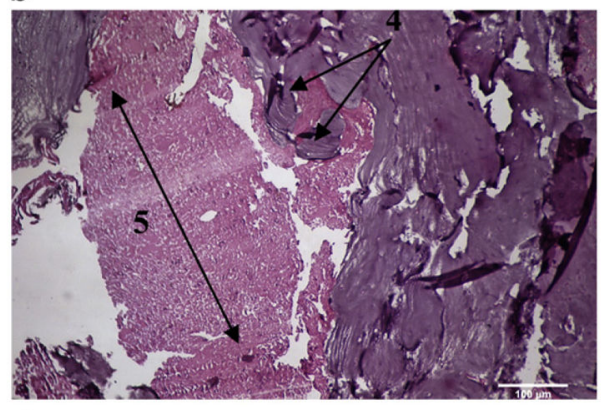

d

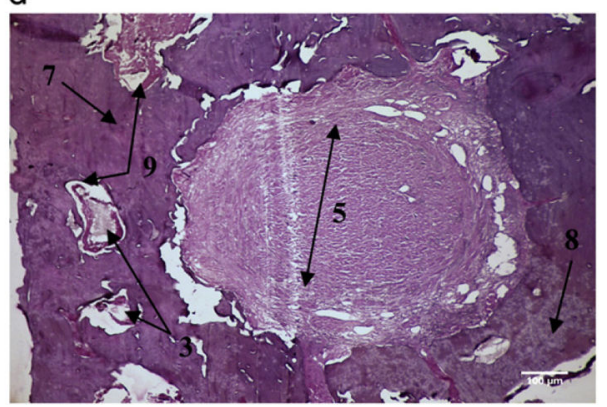

Fig. 7.

Histological analysis of the control and experimental groups of animals six weeks after the implantation: control group (a), HAp (b), HAp/D3 (c), HAp/D3/PLGA (d). Legend: 1) normal cortical bone 2) Haversian canals 3) blood vessels 4) the replacement of material with a new bone 5) implanted material 6) poorly mineralized newly formed bone 7) newly formed bone tissue 8) old bone 9) osteogenesis, 10) the process in which the newly formed tissue is replaced with mature bone 11) mature bone 12) ossification centres with large giant cells 13) ossification sites distributed in islet forms 14) creation of young bone and 15) cement lines. 
a

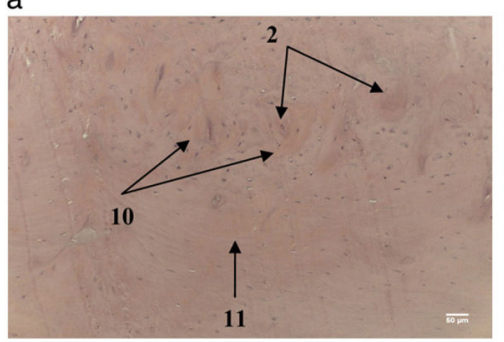

C

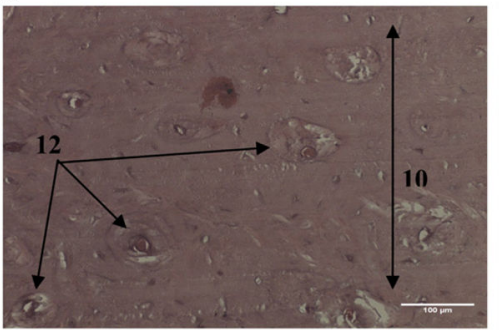

b

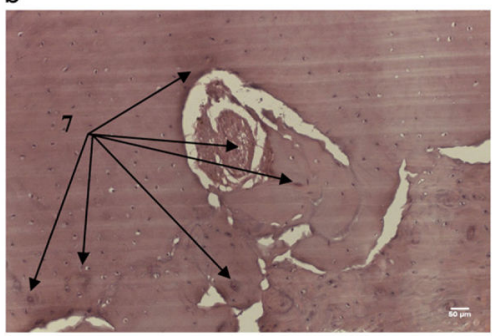

d

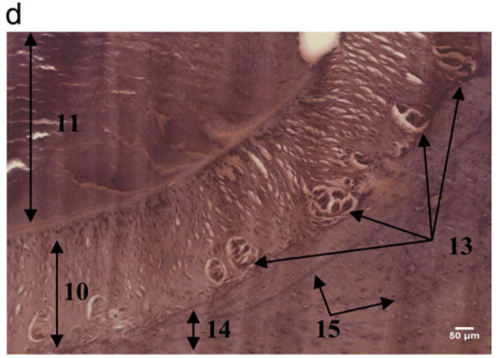

Fig. 8.

Histological analysis of the control and experimental groups of animals 24 weeks after the implantation: control group (a), HAp (b), HAp/D3 (c), HAp/D3/PLGA (d). Legend: 1) normal cortical bone, 2) Haversian canals, 3) blood vessels, 4) the replacement of material with a new bone, 5) implanted material, 6) poorly mineralized newly formed bone, 7) newly formed bone tissue, 8) old bone, 9) osteogenesis, 10) the process in which the newly formed tissue is replaced with mature bone, 11) mature bone, 12) ossification centres with large giant cells 13) ossification sites distributed in islet forms, 14) creation of young bone, 15) cement lines. 


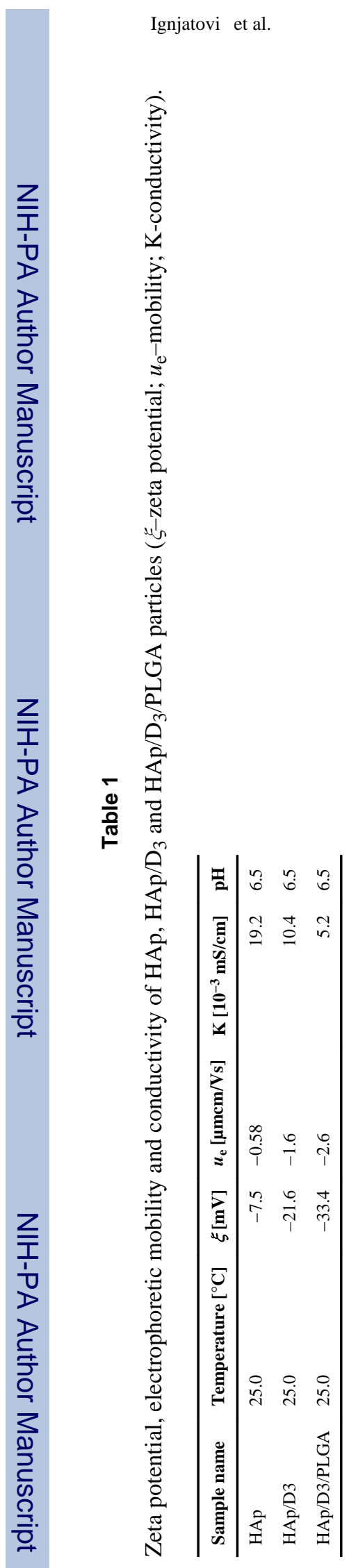

Mater Sci Eng C Mater Biol Appl. Author manuscript; available in PMC 2014 November 05. 